\title{
COMMENTARY
}

\section{High-frequency oscillatory ventilation and pediatric cardiac surgery: Yes, we can!}

\author{
Martin CJ Kneyber* \\ See related research by Bojan et al., http://ccforum.com/content/15/5/R259
}

\begin{abstract}
In the previous issue of Critical Care, Bojan and colleagues reported their experiences with highfrequency oscillatory ventilation (HFOV) after pediatric cardiac surgery. A total of 120 patients were treated with HFOV on the day of surgery, thus excluding rescue HFOV use. The main finding of the authors was that the duration of mechanical ventilation was significantly shorter in patients in whom HFOV was initiated on the day of surgery. Especially interesting about this work is that the authors used HFOV when there was evidence of pulmonary hypertension or right ventricular (RV) failure in their patients. This is an interesting approach as it is often assumed that high intra-thoracic pressures increase RV afterload and thus may enhance RV dysfunction. The findings of Bojan and colleagues may be explained by the fact that they were able to decrease the pulmonary vascular resistance by finding a proper balance between atelectasis and overdistension of the lung. It can be argued that it is possible to do so by applying positive end-expiratory pressure. But, at the same time, this may coincide with the delivery of high inspiratory pressures $\left(>30 \mathrm{~cm} \mathrm{H}_{2} \mathrm{O}\right)$. As HFOV is, in fact, a continuous positive airway pressure system, its advantage is that it is possible to maintain sufficient lung volume without large injurious pressure swings. Although the observations by Bojan and colleagues need to be confirmed in a prospective randomized trial, they have provided arguments not to rule out the early use of HFOV in pediatric cardiac surgery patients.
\end{abstract}

High-frequency oscillatory ventilation (HFOV), as used by Bojan and colleagues, is, at least in theory, an ideal tool for lung-protective ventilation as it allows effective pulmonary gas exchange with the delivery of a very small tidal volume $\left(\mathrm{V}_{\mathrm{T}}\right)$ below dead space and diminished risk of atelectrauma [1,2]. Numerous animal and clinical studies have shown clearly that mechanical ventilation (MV) itself can initiate or exacerbate lung injury, termed ventilator-induced lung injury. The application of a $V_{T}$ and the repetitive opening and closure of alveoli have been identified as important pathophysiological mechanisms [3].

Until now, only two randomized controlled trials investigating the effect of $\mathrm{HFOV}$ on patient outcome have been performed [4,5] and the larger of these included only 58 children [4]. The main finding of this study was that HFOV did not significantly improve survival (66\% with HFOV versus 59\% with conventional MV) or total ventilator days $(20 \pm 22$ days with HFOV versus $22 \pm 17$ days with conventional MV) [4]. As a consequence, HFOV is not universally employed in pediatric critical care. Also, it seems very unrealistic that any new pediatric HFOV trial will be initiated within the next few years. This means that well-designed observational studies are needed to shed light on some of the many other aspects of pediatric HFOV which remain to be explored, including the identification of patients who are most likely to benefit from HFOV, the timing of HFOV (early versus rescue), optimal oscillator settings, and monitoring during HFOV.

In the previous issue of Critical Care, Bojan and colleagues [1] reported their experiences with HFOV after pediatric cardiac surgery. A total of 120 patients were treated with HFOV on the day of surgery, thus excluding rescue HFOV use. Patients were transitioned to HFOV when hypoxemia and acidosis occurred despite increasing alveolar ventilation on conventional $\mathrm{MV}$ (if $\mathrm{V}_{\mathrm{T}}$ exceeded $10 \mathrm{~mL} / \mathrm{kg}$ ) or when there was evidence of pulmonary hypertension and right ventricular (RV) failure. The main finding was that the duration of MV was significantly shorter in patients in whom HFOV was
*Correspondence: m.c.j.kneyber@umcg.nl

Department of Paediatrics, Division of Paediatric Intensive Care, Beatrix Children's Hospital, CA 80, P.O. Box 30.001, 9700 RB Groningen, The Netherlands 
initiated on the day of surgery. This is a very positive finding in a relatively large sample size.

However, there are some concerns related to the methodology of the study and the practical use of HFOV in the authors' institution. Some of the limitations inherent to their work have been properly addressed. But their study was designed as a retrospective one introducing confounding by indication. Hence, the authors have calculated a propensity score to minimize this, although the variables chosen for calculating it raise some concern. Included were all demographic and postoperative variables that yielded a $P$ value of less than 0.10 in the univariate analysis between patients with HFOV and those without HFOV. However, it seems more rational to define, beforehand, which variables influence the decision of the attending physician to transition to HFOV and therefore which variables should be used for calculating the propensity score. As a consequence of this approach, hemodynamic and ventilator parameters have not been used. If the authors had taken these into account when calculating their propensity score, the results of the study might have been even more firm. Also, it is not customary in their institution to routinely use an open lung strategy. Arterial partial pressure of oxygen $\left(\mathrm{PaO}_{2}\right)$ increases linearly with lung volume during HFOV [6]. It is necessary, therefore, to recruit the lungs after switching to HFOV. Animal work has shown improved lung compliance and less hyaline membrane formation when such a strategy was applied $[7,8]$. The effect of increased lung volume on $\mathrm{PaO}_{2}$ is even more profound when oscillating on the deflation limb of the pressure-volume curve [9-11]. Furthermore, there is more simultaneous alveolar recruitment and overstretching on the inspiratory than on the expiratory limb of the pressure-volume curve [12]. The hysteresis of the lungs provides an additional benefit: when oscillating on the expiratory limb, less pressure is required to maintain lung volume in comparison with when oscillating on the inspiratory limb.

Nevertheless, what is especially interesting about the work of Bojan and colleagues is that they used HFOV when there was evidence of pulmonary hypertension or RV failure in their patients. This is an interesting approach as it is often assumed that high intra-thoracic pressures increase RV afterload and thus may enhance RV dysfunction. However, in a small study of 5 children after Fontan cardiac surgery [13], the use of HFOV did not result in an increase in pulmonary vascular resistance (PVR). So how can the positive findings of the study by Bojan and colleagues be explained? It is appreciated that there is a relationship between the PVR and lung volume. This typically U-shaped curve shows that the PVR is high at both residual volume and total lung capacity [14]. The curve is at its optimum (that is, lowest PVR) at 'normal' functional residual capacity. It is not uncommon for ventilated patients after cardiac surgery to suffer from pulmonary dysfunction caused by atelectasis or even acute lung injury [15]. One of the main approaches in such disease conditions is to maintain sufficient endexpiratory lung volume by the application of positive end-expiratory pressure (PEEP). However, the required level of PEEP is difficult to establish and may coincide with the delivery of high inspiratory pressures $\left(>30 \mathrm{~cm} \mathrm{H}_{2} \mathrm{O}\right.$ ). This is where HFOV comes into play. HFOV is, in fact, nothing more than a continuous positive airway pressure system with superimposed small oscillations delivering the small $\mathrm{V}_{\mathrm{T}}$. As a consequence, it is possible to maintain sufficient lung volume without large injurious pressure oscillations.

It is important to stress that the findings of Bojan and colleagues warrant prospective confirmation in a welldesigned randomized controlled trial. In the mean time, the authors are to be congratulated for their work as their study has provided arguments not to rule out the early use of HFOV in pediatric cardiac surgery patients.

\section{Abbreviations}

$\mathrm{HFOV}$, high-frequency oscillatory ventilation; $\mathrm{MV}$, mechanical ventilation; $\mathrm{PaO}_{2}$ arterial partial pressure of oxygen; PEEP, positive end-expiratory pressure; PVR, pulmonary vascular resistance; $\mathrm{RV}$, right ventricular; $\mathrm{V}_{T}$, tidal volume.

\section{Competing interests}

The author declares that he has no competing interests.

\section{Published: 24 November 2011}

\section{References}

1. Bojan M, Gioanni S, Mauriat P, Pouard P: High-frequency oscillatory ventilation and short-term outcome in neonates and infants undergoing cardiac surgery: a propensity score analysis. Crit Care 2011, 15:R259.

2. Kneyber MCJ, van Heerde M, Markhorst DG: Reflections on pediatric highfrequency oscillatory ventilation from a physiologic perspective. Respir Care 2011, in press.

3. Tremblay LN, Slutsky AS: Ventilator-induced lung injury: from the bench to the bedside. Intensive Care Med 2006, 32:24-33.

4. Arnold JH, Hanson JH, Toro-Figuero LO, Gutierrez J, Berens RJ, Anglin DL: Prospective, randomized comparison of high-frequency oscillatory ventilation and conventional mechanical ventilation in pediatric respiratory failure. Crit Care Med 1994, 22:1530-1539.

5. Samransamruajkit R, Prapphal N, Deelodegenavong J, Poovorawan Y: Plasma soluble intercellular adhesion molecule-1 (sICAM-1) in pediatric ARDS during high frequency oscillatory ventilation: a predictor of mortality. Asian Pac J Allergy Immunol 2005, 23:181-188.

6. Suzuki H, Papazoglou K, Bryan AC: Relationship between $\mathrm{PaO} 2$ and lung volume during high frequency oscillatory ventilation. Acta Paediatr Jpn 1992, 34:494-500.

7. McCulloch PR, Forkert PG, Froese AB: Lung volume maintenance prevents lung injury during high frequency oscillatory ventilation in surfactantdeficient rabbits. Am Rev Respir Dis 1988, 137:1185-1192.

8. Bond DM, McAloon J, Froese AB: Sustained inflations improve respiratory compliance during high-frequency oscillatory ventilation but not during large tidal volume positive-pressure ventilation in rabbits. Crit Care Med 1994, 22:1269-1277.

9. Goddon S, Fujino Y, Hromi JM, Kacmarek RM: Optimal mean airway pressure during high-frequency oscillation: predicted by the pressure-volume curve. Anesthesiology 2001, 94:862-869.

10. Luecke T, Meinhardt JP, Herrmann P, Weisser G, Pelosi P, Quintel M: Setting mean airway pressure during high-frequency oscillatory ventilation 
according to the static pressure--volume curve in surfactant-deficient lung injury: a computed tomography study. Anesthesiology 2003,

99:1313-1322

11. Tingay DG, Mills JF, Morley CJ, Pellicano A, Dargaville PA: The deflation limb of the pressure-volume relationship in infants during high-frequency ventilation. Am J Respir Crit Care Med 2006, 173:414-420.

12. Markhorst DG, van Genderingen HR, van Vught AJ: Static pressure-volume curve characteristics are moderate estimators of optimal airway pressures in a mathematical model of (primary/pulmonary) acute respiratory distress syndrome. Intensive Care Med 2004, 30:2086-2093.

13. Kornecki A, Shekerdemian LS, Adatia I, Bohn D: High-frequency oscillation in children after Fontan operation. Pediatr Crit Care Med 2002, 3:144-147.
14. Shekerdemian L, Bohn D: Cardiovascular effects of mechanical ventilation. Arch Dis Child 1999, 80:475-480.

15. Piantadosi CA, Schwartz DA: The acute respiratory distress syndrome. Ann Intern Med 2004, 141:460-470

doi:10.1186/cc10529

Cite this article as: Kneyber MCJ: High-frequency oscillatory ventilation and pediatric cardiac surgery: Yes, we can! Critical Care 2011, 15:1011. 